\title{
Designing an Evidence-Based Behavior Change Strategy to Promote Antibiotic Use in Primary Healthcare in Gezira State, Sudan
}

\section{Anna-Leena Lohiniva ( $\sim$ Lohinivaa@gmail.com )}

Eastern Mediterranean Regional Office: World Health Organisation Regional Office for the Eastern Mediterranean

\section{Einas S. Elwali}

Federal Ministry of Health

\section{Duha Abuobaida}

Federal Ministry of Health

\section{Ashwag Abdulrahim}

National Health Insurance Fund

\section{Paul Bukuluki}

WHO country office for Sudan

Maha Talaat

WHO Eastern Mediterranean Regional Office

\section{Research}

Keywords: antimicrobial use, antimicrobial resistance, behavior change communication, Theoretical Domains Framework, Behavior Change Wheel

Posted Date: September 15th, 2020

DOl: https://doi.org/10.21203/rs.3.rs-71506/v1

License: (c) (1) This work is licensed under a Creative Commons Attribution 4.0 International License. Read Full License 


\section{Abstract}

Background: Abuse of antibiotics is a major contributing factor to the emergence of antibiotic resistance (ABR) globally. Misuse and overuse of antibiotics is common also in Sudan. Addressing antibiotic use is a key component of AMR response.

Objectives: The project aimed to develop a theory driven behavior change strategy based on local understanding of drivers of antibiotic use at primary healthcare settings in Gezira State in Sudan. The strategy is needed to enhance the prescribers' appropriate prescription of antibiotics and to reduce the patient's demand towards unnecessary antibiotics.

Methods: The strategy was designed based on the Theoretical Domains Framework (TDF) to identify behavioral barriers and the Behavior Change Wheel to select appropriate behavior change techniques (BCTs). The process included two major elements (1) a formative qualitative research study using focus group discussions and in-depth interviews targeting prescribers and patients. (2) a knowledge coproduction workshop that utilized the results of the qualitative study and aimed to design a salient, legitimate and credible behavior change strategy identifying relevant behavior change techniques (BCTs) to overcome key barriers.

Results: The main TDF domains that emerged from the discussions with prescribers were knowledge of antibiotics and AMR, skills to answer patient demand on antibiotics, prescription habits and work exhaustion, social influences, intention to change prescription practices and environmental factors. The main TDF domains that emerged through discussions with patients were antibiotic use habits, social influences, professional role belief in capabilities and intention to change. The workshop discussions resulted in the selection of five BTCs that included education, training, modeling, enablement and persuasion.

Conclusion: This study, using the TDF and BCW taxonomy, explored the fact that antibiotic prescribing is influenced by many social and contextual factors. Knowledge co- production offered real benefits in addressing these complexities to come up with a set of context appropriate behavior change interventions.

\section{Contribution To Literature}

- The qualitative study identified barriers of changing antibiotic prescription practices of prescribers and barriers for reducing the demand of unnecessary antibiotics among patients seeking treatment in primary healthcare settings in Sudan.

- The project showed that the Theoretical domains framework and the Behavior Change Wheel can be used effectively in the context of Sudan to develop an evidence- based behavior change intervention.

\section{Introduction}


The use of antibiotics without a clear clinical indication is a major driving force of antibiotic resistance worldwide $(1,2)$. It has been estimated that up to $50 \%$ of all antimicrobials prescribed to people globally are unnecessary (3). Ways to improve appropriate antibiotic prescription behaviors vary significantly from one setting to another $(4,5)$, which highlights the need to develop context-specific approaches. These approaches require deep understanding of contextual and cultural barriers and facilitators of evidencebased behavior change; otherwise, the interventions will remain ineffective (6). The use of theory to understand the mechanism to change behavior is likewise necessary to improve the effectiveness of interventions (7-8).

The inappropriate prescription of antibiotics is common in Sudan across different types of facilities and in various geographic regions in the country (9-17). Studies show that antimicrobial use is common in the community and patients commonly request antibiotics when visiting health facilities (18). According to the Sudan pharmaceutical sector assessment in 2018 , nationally over $50 \%$ of patients visiting primary healthcare centers received antibiotics where the majority are broad-spectrum antibiotics. The national antibiotic treatment guidelines instruct prescribers to only prescribe an antibiotic when indicated and select a narrow spectrum antibiotic as the majority of patients presenting to primary healthcare settings seek care for upper respiratory tract infections (that are mostly viral and do not require antibiotic treatment), malaria, and urinary tract infections. Severe infections are always referred to secondary and tertiary healthcare facilities.

The Ministry of Health (MoH) in Sudan, in collaboration with the WHO implemented a theory-based behavior change project entitled "Tailoring Antimicrobial Resistance (AMR) Program (TAP)". TAP is a systematic methodology done to identify barriers and motivators for adopting appropriate behaviors to promote antibiotic use. It includes conducting qualitative research and utilizing the findings of the research to design evidence-based behavior change strategy through a knowledge co-production workshop (8). Together the qualitative data and the workshop constitute a methodological triangulation of data aimed at increasing confidence in the findings and creating unique insights into antibiotic prescription practices to ensure that the context in which the behaviors take place is thoroughly considered, a matter that is often missing in public health interventions (19).

This paper describes the process of developing the TAP behavior change strategy in Sudan that aimed to reduce the unnecessary prescription of antibiotics and to reduce patient's demand of antibiotics in primary health care settings.

\section{The setting}

The TAP project was conducted in Madani, the capital city of Al Gazira State in the east-central region of Sudan. The city has a population of 3.5 million whereas the population of the state reaches more than 5 million, with 93 hospitals and 984 primary health care centers (PHCC) the majority of which are in Madani (20). The MOH selected eight PHCCs for the pilot distributed geographically across the city. Each PHCC includes 2 -5 doctors and an average of 660 patient visits per month. 


\section{Methodology}

The TAP behavior change strategy development process was based on two essential components (A) a formative qualitative research study that aimed to explore the factors influencing physicians' prescribing practices of antibiotics as well as patient's demand for antibiotics and (B) a knowledge co-production workshop that utilized the findings of the qualitative research to design a salient, legitimate and credible behavior change strategy (21-26). Standards for reporting qualitative research (SRQR) were used to design the project.

\section{Qualitative research study}

\section{Theoretical framework}

The qualitative study used the theoretical domains framework (TDF) to explore the underlying causes for the inappropriate use of antibiotics. The framework consists of 14 domains that include knowledge, skills, social environment, professional role, memory and decision-making process, environmental factors, goals, intentions to change, optimism, reinforcement, behavior regulation, belief in capabilities, beliefs in consequences, and emotions (27-28). The domains were defined and adapted for study purposes. See TDF domains and definitions in Table 1. 
Table 1

Definitions of the domains of Theoretical Domains framework (TDF) as adapted for the TAP

Domain Definition for TAP

$\begin{array}{ll}\text { Knowledge } & \text { Knowledge of antibiotics and antimicrobial resistance } \\ \text { Skills } & \text { Communication and negotiation skills to answer patient demands }\end{array}$

Memory, attention Prescription habits and psychological reactions such as exhaustion and decision process

Antibiotic use habits

Behavior regulation Having made plans to change behavior

Social influence Social networks, social norms

Environmental External factors

factors

Professional role Reputation, professional relations, respect towards prescribers

Intentions, goals, Intentions, goals to change, believing that the change is something positive positivism

Beliefs in capabilities Doctors: Belief that one can stop the prescription of unnecessary antibiotics

Patients: Belief that one can stop requesting antibiotics from doctors

Belief in Belief on outcomes if prescribers do not reduce prescription of broadconsequences $\quad$ spectrum antibiotics / if patients do not stop demanding antibiotics

Reinforcement Positive or negative feedback, follow up for prescription of consumption of antibiotics

Emotions $\quad$ Feelings that impact change positively or negatively

\section{Qualitative study data collection tools:}

The study relied on a mix of in-depth interviews (IDI) and focus group discussions (FGD). Question guides covering the 14 domains of the TDF were developed accordingly.

\section{Sampling of study subjects:}

A purposive sample was drawn to gain diversity by including various types of prescribers and patients in the study. Data saturation was the principle for obtaining an adequate sample size. However, a minimum sample size for initial data collection was set at 10 IDI for prescribers and eight FGDs for patients, followed by three additional interviews until new themes were no longer produced (29).

\section{Data collection for the qualitative study:}


A field team of seven well trained public health professionals conducted the in-depth interviews and the FGDs over two weeks' time period. Data collection began by piloting and modifying question guides followed by conducting an average of 3-4 interviews or FGDs daily. The interviews lasted 25-40 minutes while focus groups were from 60-90 minutes. Each day ended with a debriefing session where the teams shared key findings. Interview techniques and questions were modified accordingly during the process.

Health officials in Gezira State coordinated the recruitment of study participants. Informed written consent was obtained from all participants. All interviews were conducted in a private space and no identifiers were collected to ensure confidentiality. Interviews with prescribers were conducted in the primary healthcare centers. Patients were recruited from the waiting areas of health care centers.

\section{Analysis of qualitative data:}

The data analysis process began in the field with debriefing sessions that generated field notes used as a data source for triangulation purposes. Four members of the research team who were also part of the data collection team participated in the analysis. TDF served as a framework for analysis (30). The audio data was managed using a methodology called rapid identification of themes from audio-recording (RITA) that allows researchers to code and analyze qualitative data by transcribing only the parts that relate to the TDF domains of behavior (31).

The team discussed the domains of the framework to reach to an understanding of how each domain was defined, followed by listening to participant responses from audio recordings, considering their relevance to the TDF domains, transcribing and translating relevant sections directly from the audio recordings. All transcribed sections were reviewed by the lead investigator and re-discussed with the team to reduce bias. In the second step, the lead investigator developed a chart based on domains and organized the data from all interviews into these domains. This was followed by the identification of codes and themes in each domain based on the principles of thematic analysis that aims to identify patterned meaning across datasets (32). The codes and themes were reviewed by other team members before the final interpretation of the data which included developing a set of overarching themes used as a base for developing a behavior change intervention (30).

\section{Knowledge co-production workshop}

A multidisciplinary group of Sudanese and international experts in public health, pharmacology, social sciences and communication as well as treating physicians of primary healthcare participated in the workshop. The three-day workshop aimed to create an effective, culturally acceptable, practical behavior change intervention that is implementable on a large scale. It was based on the Behavior Change Wheel (BCW) framework for change that consists of three domains; capability, opportunity, and motivation that interact to explain behavior as shown in Table 2 (the 'COM-B' system) which shows how TDV domains are merged into BCW COM_B $(8,33)$.

Table 2. COMB domains combined with TDF domains 
Capability

-TDF DOMAINS

- Knolwedge

-Skills

- Memory, habits

-Behavioral regulations
Opportunity

-TDF DOMAINS

-Social

-Environmental

\section{Motivation}

-TDF DOMAINS

- Professional role

- Belief in consequences

-Belief in capabilites

- Intentions and goals

- Optimism

The BCW further provided a systematic and theoretically guided method for identifying the types of BCTs that are expected to be effective for each COMB domain. The BCW includes nine BCTs : education, persuasion, incentivization, coercion, training, restriction, training, environmental restructuring, and enablement, as well as seven policy categories including guidelines, environmental planning, regulation, service provision, legislation, communication planning/marketing, and fiscal measures (8).

The outcome of the workshop included a list of behavioral domains and techniques that aimed to reduce the prescription of unnecessary antibiotics and to reduce patient demand for antibiotics in primary healthcare facilities.

\section{Findings}

First, we will present the prescriber related findings of the qualitative study and the knowledge co production workshop followed by description of patient related findings of the qualitative study and the workshop.

\section{Prescribers}

\section{A. Qualitative formative study}

\section{Participant characteristics}

The sample included 20 prescribers including general practitioners (50\%), family medicine practitioners $(44 \%)$ and dentists (6\%). Most were females (69\%) and from Gezira State (82\%). Prescribers' professional experience ranged from $1-24$ years (median $=5.4$ years) .

\section{Factors influencing prescription of antibiotics}

Seven TDF framework domains out of fourteen influenced the prescription practices were identified; knowledge on antibiotics and AMR, skills to answer patient demands, prescription habits and psychological reactions, social influences, intentions to change current prescription practices, belief in capabilities to change prescription practices, and environmental factors. As the study is operational, the findings of each domain are described separately to further place them in the behavior change framework. 


\section{Knowledge on antibiotics and AMR}

Respondents explained that they don't have enough knowledge or guidelines on the various classification and types of antibiotics as well as clinical indications. They believed that their knowledge was outdated. They also rarely meet representatives from pharmaceutical companies whom they considered potential sources of new information on antibiotics.

"I no longer remember which antibiotics are broad-spectrum and which are narrow spectrum. Therefore, it is not easy for me to change my practices." (A female general practitioner) Respondents did not think that AMR was a much-discussed topic among doctors in Sudan. They explained witnessing patients with resistant infections in their practice but not knowing the actual scope of the problem globally or nationally.

"Yes, we see cases of resistant bacteria. We just change the antibiotic until it works. I don't know if there is more resistance than before." (A male general practitioner)

\section{Physician skills to answer patient demands of antibiotics}

Respondents felt that they lack capabilities to convince patients who demand unnecessary antibiotics. This was considered particularly challenging with patients who had predetermined the need for a specific type of antibiotic and those who had health insurance program that provides free medications. Respondents explained that patients also used emotional pressure on prescribers presenting themselves as underprivileged citizens for whom antibiotics were the only available resource.

"There are patients who have diagnosed themselves based on their symptoms, decided on the investigations and the treatment required. Not much you can do to convince them otherwise." (A female pediatrician)

\section{Habits and exhaustion}

Treating physicians described various prescription standards and habits they developed over the years. For example, some explained prescribing antibiotics to all patients with symptoms of urinary tract infections or typhoid. Others described that they always prescribe broad spectrum antibiotics to all patients coming from long distances and to patients at risk of secondary bacterial infections.

"I have patients who walk three hours to come to the facility, so I know that they won't be coming back for a follow-up visit. That's when I prescribe them broad-spectrum antibiotics" (A female dentist)

Respondents highlighted that when they were exhausted from work, they just respond to the patients request and prescribe unnecessary antibiotics without discussion.

"But when you are tired, you have no energy to debate with your patient." (A female general practitioner)

\section{Social influences}


Respondents' social networks were often mixed with their professional networks meaning that patients were often also friends, neighbors or family members that made refusal to prescribe unnecessary antibiotics difficult.

"It is hard if I know the patients and I know his family. I am embarrassed to deny his requests. It is not easy." (A female general practitioner)

On the other hand, some respondents also noted that respect and trust among family and friends made antibiotic negotiations with them easier.

"My family always consults with me, they trust me and I always give them my honest answer to everything. So I don't have pressure to prescribe from that direction." (A female general practitioner)

\section{Intention to change prescription practices of treating physicians}

Respondents explained that they had never paid attention to their antibiotic prescription practices and they don't see any urgency to change them. They clarified that their patients would not accept alterations in their practices. Others explained that they have no intention to change their practices as they are observing an increasing number of patients with uncured infections that makes them always prescribe antibiotics that are broad spectrum.

"No, I don't think this is what I will be doing. In general, doctors are moving to stronger antibiotics, especially if you go to private clinics you will find this." (A male general practitioner). Prescribers also believed that reducing prescriptions of antibiotics would not eliminate the unnecessary use as patients could always buy them from community pharmacies.

"Pharmacies are always open for patients." (A female general practitioner)

Respondents noted that patients who treat themselves with antibiotics (self-medication practices) for long time periods before visiting the health centers, made it challenging to change the type of prescribed antibiotic to narrow-spectrum.

"Many patients come to me after they had tried several antibiotics. I get very confused and wonder what antibiotics I should prescribe. Narrow spectrum is rarely possible" ( A male general practitioner)

\section{Environmental factors}

Respondents highlighted that the health insurance system which provides free treatment to patients encouraged them to demand antibiotics and perceive this as their right irrespective of the clinical indication.

"All of my patients, but especially those with health insurance, expect to get antibiotics from our center. This is the main reason they come here." (A female general practitioner) 
Prescribers explained that the availability of narrow spectrum antibiotics was rather limited in PHCC, and the availability of broad-spectrum antibiotics has increased over the years which also encourage their prescription.

\section{B. Knowledge co-production workshop for prescriber intervention}

Workshop participants reviewed the findings of the qualitative research and discussed the type of barrier each domain represented for changing the prescription practices of doctors in primary healthcare centers. This was followed by discussions about which of these domains and barriers were relevant, acceptable and practical in the context of Sudan. The selected barriers included lack of knowledge on antibiotics and AMR, lack of negotiation skills to convince patients not to take unnecessary antibiotics, and limited intention to change behavior.

Based on the BCW, the workshop participants agreed that lack of knowledge should be addressed with an educational BCT to enhance the knowledge of prescribers on the principles of antibiotic treatment and provide background on AMR. Discussions also focused on the importance of a training based BCT to improve negotiation skills to answer patient's demand.

Workshop participants agreed that educational interventions are generally appreciated by physicians and these activities could be organized on a large scale. However, they recommended that building negotiation skills will attract fewer clinicians as it is a non-medical training. Enablement and modelling were selected as BCTs to motivate change by promoting ethical principles and by giving examples of change. Modelling was considered highly context appropriate in a hierarchical health system were senior doctors are highly respected and accordingly could be used to inspire change. The behaviour change framework for prescribers can be found in Table 3.

Table 3

Behavior change framework for prescribers

\begin{tabular}{|lllll|}
\hline TDF domain & COMB & Barrier & Objective & \multicolumn{1}{l|}{$\begin{array}{l}\text { Intervention } \\
\text { function }\end{array}$} \\
\hline Knowledge & Capability & $\begin{array}{l}\text { Lack of } \\
\text { knowledge of } \\
\text { antibiotics and } \\
\text { AMR }\end{array}$ & $\begin{array}{l}\text { Improve knowledge about the } \\
\text { principles of antibiotic therapy, } \\
\text { the epidemiology of AMR }\end{array}$ & Education \\
\hline Skills & Capability & $\begin{array}{l}\text { Lack of } \\
\text { communication } \\
\text { skills }\end{array}$ & $\begin{array}{l}\text { Improve negotiation sills to } \\
\text { answer patient demand }\end{array}$ & Training \\
\hline $\begin{array}{l}\text { Intention to } \\
\text { change } \\
\text { prescription } \\
\text { practices }\end{array}$ & Motivation & $\begin{array}{l}\text { No intention to } \\
\text { change } \\
\text { behavior }\end{array}$ & $\begin{array}{l}\text { Motivate change by promoting } \\
\text { ethical principles and by giving } \\
\text { examples of change }\end{array}$ & Enablement \\
\hline
\end{tabular}




\section{A. Qualitative formative study}

\section{Participant characteristics}

Eight FGDs were conducted with 94 patients. Most were women (73.4\%) originating from Gezira State (97.9\%). Participants had completed various levels of education including university (32\%), preparatory school $(6.3 \%)$, secondary school $(36.2 \%)$, or primary school $(10.6 \%)$. Some respondents had no schooling (8.6\%).

\section{Factors influencing patient behavior}

Five domains of TDF related to patient demand for antibiotics were identified: antibiotic use habits, social influences, professional role of prescribers, belief in capabilities to stop demanding antibiotics, and intention to stop demanding antibiotics.

\section{Antibiotic use habits}

Respondents explained they consume antibiotics all times for any health problem or symptoms including common cold, recurrent infections such as malaria, pain, fever or fatigue. They also explained keeping antibiotics at home in case someone gets sick. This type of home pharmacy is usually filled before the holidays.

"In the community where I live, we commonly use Cipro for typhoid and everyone uses Amoclan. It works." (A woman from El Mekky village)

Respondents explained that many people usually have preferable specific types of antibiotics that they use for all health problems and symptoms. It is usually an antibiotic that provided good results in the past. They also believe antibiotics are essential for cure; believing one could not recover from the infections without the use of antibiotics.

"People from that area commonly come to our village health unit and pharmacies to buy the same type of antibiotic. They all use the same antibiotic." (A woman from Al Atra village)

Antibiotics were considered the fastest, strongest type of medication. Imported and more expensive antibiotics were perceived more effective than local or cheaper ones.

"I always insist on the Jordanian ones. Sudanese antibiotics are weak." (Woman from Debagha village)

\section{Social influences}

Respondents highlighted the important role their families, friends and neighbors played in advising them on the use of antibiotics. Usually elderly females in the household were the most knowledgeable. Mothers of young children frequently chatted with one another and learned about antibiotics through experience 
and word by mouth. Respondents also explained that villages had knowledgeable individuals who provided advice about antibiotics.

"I can advise my neighbor on what to give to a sick child and even tell her the dosage without weighing her." (A woman from Arkaeet village)

\section{Professional role}

Respondents frequently highlighted that many doctors prescribed the same antibiotic to all patients regardless of their health problem blaming physicians of not having enough information on antibiotics.

"Some doctors prescribe the same antibiotic over and over again ... they may not know much." (A woman from El Mekky village)

Pharmacists, on the other hand, were often seen as being able to diagnose patients and prescribe antibiotics. Respondents explained that they frequently consulted community pharmacists on antibiotic use.

"If we talk about senior pharmacists, they are comparable to medical doctors. They are called doctors too." (A man from Al Atra village)

\section{Belief in personal capabilities}

Respondents believed in their ability to diagnose illnesses and to choose the type of antibiotic required, especially for common infections. They also believed that they knew best what works for them; not all antibiotics were believed to work for everyone.

"I know what is effective for me not the doctor. She does not know me so it is difficult for her to know what works best." (A woman from Debagha village)

\section{Intention to change behaviors}

Respondents had no plans or goals to change their current practices of insisting on certain types of antibiotics.

"I am not planning to stop asking for antibiotics. We need them." (A woman from Arkaweet village)

\section{Knowledge co-production workshop for prescriber intervention}

The workshop participants identified three barriers to be addressed in the behavior change strategy including habits, social influences, and intention to change behaviors (Mitchie et al 2014). They recommended to use enablement as a BCT to change habits by addressing misconceptions that patients had about antibiotics. They also recommended to use enablement by building trust between the two parties. BCTs addressing social aspects were considered highly suitable for the context of Sudan. In addition, workshop participants believed that intention to stop demanding antibiotic should be increased 
by providing information on consequences of such behaviors, including the spread of AMR. Workshop participants thought that patients would be eager to receive such as an educational intervention. It would be easy to implement and even to run on large scale as the network of health units is large in Sudan. the behavior change framework can be found in Table 4 .

Table 4

Behavior change framework for patients

\begin{tabular}{|lllll|}
\hline $\begin{array}{l}\text { TDF } \\
\text { domain }\end{array}$ & COMB & Barrier & Objective & $\begin{array}{l}\text { Intervention } \\
\text { function }\end{array}$ \\
\hline Habits & Capability & $\begin{array}{l}\text { Antibiotic use habits are } \\
\text { deeply rooted in } \\
\text { misconceptions }\end{array}$ & $\begin{array}{l}\text { Breaking normative } \\
\text { behavior and linked } \\
\text { misconceptions }\end{array}$ & Enablement \\
\hline $\begin{array}{l}\text { Social } \\
\text { influences }\end{array}$ & Opportunity & Trust in community advice & $\begin{array}{l}\text { Building trust between } \\
\text { prescribers and patients }\end{array}$ & Enablement \\
\hline Intention & Motivation & $\begin{array}{l}\text { No intention to stop } \\
\text { requesting antibiotics. }\end{array}$ & $\begin{array}{l}\text { To discuss the } \\
\text { implications of AMR }\end{array}$ & Education \\
\hline
\end{tabular}

\section{Discussion}

To our knowledge this is the first designed theory based behavior change intervention strategy that applied the TDF and the BCW to improve physicians' antibiotic prescribing practices and to reduce patient demand for unnecessary antibiotics in primary healthcare settings in Sudan adding to the growing body of evidence for the utility of TDF and BCW.

The findings of the qualitative study have provided valuable information exploring the prescribing and consumption culture in Sudan. The study found that these processes are complex and influenced by knowledge, social and cultural factors alike. The study identified seven overlapping TDF domains representing barriers to prescribers' appropriate use of antibiotics, three of which were selected by the knowledge co-production workshop participants to be addressed in the behavior change intervention: lack of knowledge, skills, and intention to change behavior. The study also identified five TDF domains that affect patients to demand unnecessary antibiotics, three of which were included in the behavior change strategy: habits, social influences and lack of intention to change behavior. The study demonstrated the complexity of the influences that are linked with the behaviors and the importance of developing a multifactorial intervention as identified in several studies (34-36).

The study findings align with the growing body of research highlighting that although sufficient knowledge is likely to be a prerequisite for the appropriate prescription of antibiotics, yet increasing knowledge alone has little impact on changing antibiotic prescription practices unless all behavioral determinants and social norms influencing behaviors are addressed (37-39).

An important finding of the qualitative study was that both prescribers and patients lacked motivation to change their current practices. They did not think that their current antibiotic prescription or consumption 
practices require modification and, therefore, had no intention to change. This finding is somewhat contradictory to recent studies in other countries where healthcare workers admitted the need to make a change and in some cases they had even made plans how to modify their practices $(19,40)$. The efforts to identify more effective methods of changing intentions should also include promotion of intention stability and sustainability (41).

Lack of skills to answer patient demand was a prescriber-related driver of unnecessary prescription of antibiotics. Convincing patients during short consultations was considered challenging. A recent study in Tanzania concluded likewise that an emphasis on communication skills is crucial in helping physicians deal with customers who demand antibiotics (42). Moreover, a review of effectiveness of physiciantargeted interventions to improve antibiotic use found that communication skills training had one of the largest effects on behavior change (43).

The findings of the qualitative study also indicated that patients trusted their social networks more than doctors regarding antibiotics highlighting the importance of social factors and trust building components. Trust among family and friends with regard to health-related matters has been identified in many cultural settings $(44,45)$.

Knowledge co-production was a valuable methodology to identify the intervention functions as it ensures that the proposed BCTs are practical in the local context and could be conducted within the existing structures of Sudan. Knowledge co-production also enriched the discussions $(24,45-48)$, which culminated in the identification of four BCTs for prescribers to address the selected TDF behavioral domain that included education, training, enablement and modeling, as well as two BCTs for patients that included education and enablement.

Previous studies in the region indicate that educational interventions alone have limited impact (49-51) but in many successful multifaceted interventions, educational components are included $(9,17,52,53)$. Enablement interventions are specific for intervening on factors that block the behavior change (8) Mitchie et al 2013). In this project it includes breaking normative behavior and linked misconceptions and building trust between prescribers and patients. Successful norm changes often go together with policy changes. Therefore, a policy analysis could be a beneficial methodology to understand and intervene in the policy environment (54-55). For example, in Sudan the national health insurance policy with free medical services and a co-payment system with $25 \%$ patient payment for medications is likely to encourage habitual antibiotic use in Sudan which must be taken into consideration when aiming to change normative behaviors. Management trust building interventions that have worked in other countries in the world should be considered (56). Modelling interventions that use role models as an agent of change usually serve three distinct functions in which they influence goals and motivation: acting as behavioral models, representing the possible, and being inspirational (57). The selection of role model doctors that are expected to act as motivators should be based on these factors accordingly.

The study had some limitations. The intervention focused only on behavioral factors although environmental factors such limited availability of narrow spectrum antibiotics was identified as a driver 
for unnecessary prescription of broad-spectrum antibiotics. Addressing such structural changes was outside the scope of the project. As this was an operational study, the findings were analyzed only within the TDF domains without analyzing connections between the domains as a means to ensure the COMB exercise that was based on identifying intervention functions for separate domains was kept manageable for the workshop participants.

\section{Conclusions}

This study provided detailed insights into behavioral factors that influence the prescription and use of antibiotics among prescribers and patients, respectively, in primary healthcare in Sudan. The incorporation of behavioral theories - TDF and BCT taxonomy - supported the identification of key factors that are integral to understanding antibiotic use in primary healthcare in Sudan: antibiotic use habits, social influences, and lack of intention to change current practices as well as the importance of negotiation skills to convince patients not to use antibiotics unnecessarily.

Based on the results of this study, a detailed behavior change intervention strategy will be implemented and evaluated in Sudan to promote antibiotic prescription practices in primary healthcare settings in Sudan, where a follow up paper will be published to describe the impact of implementing the designed intervention.

\section{Declarations}

\section{Ethics approval and consent to participate}

The project and TAP methodology received ethical approval by the Ministry of Health in Sudan ethical review board followed by the approval of the WHO Eastern Mediterranean Regional Office ethical board

\section{Consent for publication}

Not applicable

\section{Availability of data and materials}

The datasets generated during and the current study are not publicly available are available from the corresponding author on reasonable request.

\section{Competing interests}

No competing interests

\section{Funding}

The project was funded by the German Fund 


\section{Authors' contributions}

All authors were involved in the conceptualizing of the study, ALL, EE, AD, AM were engaged in the preparation of materials, data collection, data analysis, ALL drafted the manuscript, MT supervised the study and commented on and aided in the drafting of the manuscript. All authors read and approved the final manuscript

\section{Acknowledgements}

We would like to express our sincere appreciation to Abdallah Abdalkareem, Head of public health laboratories, Federal Ministry of Health in Sudan, Hassan Abdulrahman director General of Pharmacy, Federal Ministry of Health in Sudan and Naeema Al Gasser, representative of WHO Sudan office for their continuous support and valuable suggestions during the planning and development of the project.

We would like the acknowledge TAP working group members Asmaa Hashim, Badraldin Hajnour, Eilaf Ali Mohamed, Isra Abozaid Saieed, Eman Mukhtar, Huda Haroun Maha Fathalrahman, Maweia Hassan Ahmed, Omer Albadri Mohamed Sara izz Sara Abuzaid, Marwa Fadlallah, Reem shourbagy , Rayan Elshaikh , Sara Babiker Mustafa, Sara Ezzeldin, Sara Omer Makki, Abdalla and, Waleed Siddiq of their contribution in developing the project concept and their continuous input in the planning and the execution of the project.

We would also like to express appreciation to the efforts of health officials from Gezira state, Abubakr Khidir Yousif, Dafallah Ahmed Dafallah, Maha Mirghani , Merghani Abdalrahman , Merghani Abdalrahman, Rana Samir Mohamed, Sana Musa Mahmoud, Sitalbnat Yasseen Elsadeeq, Summaia Kabbar for their endless efforts to support the project.

\section{References}

1. Holmes, AH, Morre, LS, Sundsfjord, A, Steinbakk, M, Regami, S, Karkev, et al.Understanding the mechanisms and drivers of antimicrobial resistance, Lancet. 2016; 387(10014):176-87. doi: 10.1016/S0140-6736(15)00473-0. Epub 2015 Nov 18.

2. Laxminarayan, R, Duse, A, Wattal, C, Zaidi, A, Wertheim H, Sumpradit, N, et al.Antibiotic resistance-the need for global solutions'. Lancet Infect Dis. 2013;13:1057-98.

3. Centres for Disease Control and Prevention. Antibiotic resistance threats in the United States. 2013. https://www.cdc.gov/drugresistance/pdf/ar-threats-2013-508.pdf. Accessed 19 October 2019.

4. Oberje, E, Tanle, M \& Jeurissen P 2017,' Antimicrobial stewardship initiatives throughout Europe: Porven value for money', Infect Dis Rep, vol.30. no.9.pp.6800 doi: 10.4081/idr.2017.6800.

5. Van Dijck, C, Vlieghe, E \& Cox, J 2018,'Antibiotic stewardship interventions in hospitals in low-and middle -income countries: a systematic review, Bull World Health Organ, vol.94, no. 4, pp. 266-280. doi: 10.2471/BLT.17.203448 
6. Charani, E, Tarrant, C, Moorthy, K, Sevdalis, N, Brennan, L, Homes A. Understanding antibiotic decision making in surgery-a qualitative analysis.'. Clin Microbiol Infect. 2017; 23(10):752-760. doi: 10.1016/j.cmi.2017.03.013

7. Colquhoun HL, Brehaut, JC, Sales, A Ivers, N, Grimshaw, J, Michie S, et al . A systematic Review of the use of theory in randomized controlled trials of audit and feedback. Implement science. 2013; 8(66). https://implementationscience.biomedcentral.com/track/pdf/10.1186/1748-5908-8-66. Last accessed 19.10.2019

8. Michie, S, van Stralen, MM, West, R.The behaviour change wheel: A new method for characterising and designing behaviour change interventions. Implementation Science. 2011. vol.6 (42) https://doi.org/10.1186/1748-5908-6-42. Accessed 19 October 2019

9. Eltayeb, I, Awad, Al, Mohamed -Salih, MS, Daffa-Alla, MA, Ahmed, MB, Ogail, MA, et al. Changing the prescribing patterns of sexually transmitted infections in the White Nile Region of Sudan. Sex Transm Infect. 2005; 81:4260427

10. Elsalahi, SH, Mudawi, MME, Ahmed, AAE. Evaluation of prescribing patterns in primary healthcare centers of Khartoum State, Sudan. An International Journal of Advances in Pharmaceutical Science. 2014; 5(4): 2242-2247.

11. Mustafa I (2012) The pattern of medicine use in Sudan: a cross-sectional study at National Health Insurance Fund setting in 2012. Swiss Tropical and Public Health Institute.

12. Abdelmoneim IA, ElTayeb, IB, Omer ZB. Investigation of drug use in health centers of Khartoum State. Sudan med Journal.1999; 37(2): 21-26

13. Mahmoud, RK, Kheder, SI, Ali, HM (2014) Prescribing rationality in Khartoum state, Sudan: An update. Sudan Medical Monitor. 2014; 9(2): 61-65.

14. Kheder SI. Cephalosporin usage and resistance trend in Sudanese hospital surgical wards. J Pharm Biomed Sci. 2011b; 11: 1-6.

15. Kheder SI, Ali HM. WHO pharmaceutical Situation Assessment Level II. Health facilities survey in Khartoum State, Khartoum RDF. 2007; 1-55.

16. Kheder SI. Physicians' knowledge and perception of antimicrobial resistance: A survey in Khartoum State hospital setting. British Journal of Pharmaceutical Research. 2013 ;3(3): 347-362.

17. Awad, Al, Himad, HA. Drug-use practices in teaching hospitals of Khartoum state, Sudan. Eur J Clin Pharmacol. 2006; 62 (12): 1087-1093.

18. Tangcharoensathen V, Chanvatik, S \& Sommanustwwchai A (2018), Complex determinants of inappropriate use of antibiotics, Bull World Health Organ, 96(2): 141-144, doi: 2471/BLT.17.199687

19. Charani, E, Castro-Sanchez, E, Sevdalis, N, Kyratsis, Y, Drumright, L, Shah, et al. Understanding the determinants of antimicrobial prescribing within hospitals: The role of 'prescribing etiquette'. Clinical Infectious 2013; 57(2):188-196, doi: 10.1093/cid/cit212

20. Central Bureau of Statistics (CBS), UNICEF Sudan 2016. Multiple Cluster Survey 2014 of Sudan, Final Report, Sudan, Khartoum. 
21. Burman, A. The political ontology of climate change: Moral meteorology, climate justice, and the collegiality of reality in the Bolivian Andes'. Journal of Political Ecology. 2017; 24(1): 921-930. https://doi.org/2458/v24i1.20974;

22. Cash, D, Clark, W, Alcock, F, Dickson, N, Eckley, N, Guston, D, et al. Knowledge systems for sustainable development, Proceedings of the National Academy of Sciences. 2003; 100(14): 8086-8091. https://doi.org/10.1073/pnas.1231332100

23. Dilling, L, Lemos, MC.Creating usable science: Opportunities and constraints for climate knowledge use and their implications for science policy. Global Environmental Change. 2010; 21(2):680-689. https:// doi.org/10.1016/j.gloenvcha.2010.11.006

24. van Kerkhoff, L \& Lebel, L 2015, 'Co-productive capacities: Re-thinking science-governance relations in a diverse world', Ecology and Society, vol 20, no 1, viewed 9 August 2019, https://doi.org/10.5751/ES-07188-200114

25. Lemos,M, Morehouse, B. The co-production of science and policy in integrated climate assessments', Global Environmental Change. 2005; 15(1): 57-68. https://doi.org/10.1016/j.gloenvcha.2004.09.004

26. Mauser,W, Klepper, G, Ricem, M, Schmalzbauer, BS, Hackmann, H, Leemans, R, et al. Trans disciplinary global change research: The co-creation of knowledge for sustainability. Current Opinion in Environmental Sustainability,2013; 5(3):420-431. Accessed 19 October 2019 2019https://doi.org/10.1016/j.cosust.2013.07.001

27. Fleming, A, Bradley, C, Cullinan, S, Bryne, S. Antibiotic prescribing in long-term care facilities: a qualitative, multidisciplinary investigation. BMJ Open. 2014;4(11): e006442 http://dx.doi.org/10.1136/bmjopen-2014-006442. Accessed 19.10.2019.

28. Phillips, C, Marshall, A, Chaves, N, Jankelowitz, S, Lin, I, Loy, C, Ress, G, Sakzewski, L, Thomas S, To, T, Wilkinson, S \& Mitchie, S 2015,'Experiences of using the Theoretical Domains Framework across diverse clinical environments: a qualitative study', Journal of Multidisciplinary Healthcare, vol. 8, pp. $139-146$

29. Francis JJ, Johnston, M, Roberstson, C, Glidewell, L, Entwistle, V, Eccles, MP. Et al.What is an adequate sample size? Operationalizing data saturation for theory based interview studies. Psychol Health.2010; (10):1229-45. doi: 10.1080/08870440903194015.

30. Atkins, L, Francis, J, Islam ,R, O'Connor, D, Patey, A, Ivers, N, et al. A guide using the theoretical domains framework of behavior change to investigate implementation problems. Implementation Science. 2017; 12(1): doi: 10.1186/s13012-017-0605-9

31. Neil, J, Neil, Z, VanDyke, E \& Kornbluh, M 2015, 'Expediting the analysis of qualitative data in evaluation: A procedure for Rapid identification of themes from audio recordings', American Journal of Evaluation, vol 36, no.1, pp.118-132.

32. Braun, V, Clarke, V. Using thematic analysis in psychology. Qualitative Research in Psychology. 2006; 3(2): 77-101.

33. Clarke, A, Jhamb, M, Bennetr, P. 2019, 'Barriers and facilitators for engagement and implementation of exercise in en-stafe kidney disease: Future theory-based interventions using the Behavior Change 
Wheel, Semin Dial. 2019; 32(4):308-319. doi: 10.1111/sdi.

34. Davey, P, Marwick, A, Scott, CL, Charani, E, Mcneil, K, Brown, et al.Interventions to improve antibiotic prescribing practices for hospital inpatients. Cochrane Database Syst. 2017; Rev, 2, CD003543.

35. Ivanovska, V, Holloway, KA. Interventions to improve antibiotic prescribing in upper middle income countries: A systematic review of the literature 1990-2009. Maced. J. Med. Sci, 2013; 6: 84-91.

36. Molero JM, Moragas A, González López-Valcárcel B, Bjerrum L, Cots JM, Llor C. Reducing antibiotic prescribing for lower respiratory tract infections 6 years after a multifaceted intervention. Int J Clin Pract,_e13312. doi: 10.1111/ijcp.13312.]

37. Charani, E, Tarrant, C, Moorthy, K, Sevdalis, N, Brennan, L, Homes A. Understanding antibiotic decision making in surgery-a qualitative analysis.'. Clin Microbiol Infect. 2017; 23(10):752-760. doi: 10.1016/j.cmi.2017.03.013

38. Pearson M, Chandler C 2019. Knowing antimicrobial resistance in practice: a multi-country qualitative study with human and animal healthcare professionals. Glob Health Action. 12(1): 1599560. doi. 1080/16549716.2019.1599560.

39. Haenssgen, MJ, Xayavong, T, Charoenboon, N, Warapikuptanun ,P, Khine Zaw, Y· The Consequences of AMR Education and Awareness Raising: Outputs, Outcomes, and Behavioural Impacts of an Antibiotic-Related Educational Activity in Lao PDR. Antibiotics (Basel). 2018; 7(4). pii: E95. doi: 10.3390/antibiotics7040095.

40. Broom, A, Broom, J, Kirby E. Cultures of resistance? A Bourdieusian analysis of doctors' antibiotic prescribing. Soc Sci Med.2014;110:81-88.

41. Webb TL 2006. Does changing behavioral intentions engender behavior change? A meta-analysis of the experimental evidence. Psychological Bulletin, 132(2): 249-268.

42. Dillip, A, Embrey, M, Shekalaghe ,E, Ross-Degnan, D, Vialle-Valentin, C, Kimatta, S. et al. What motivates antibiotic dispensing in accredited drug dispensing outlets in Tanzania? A qualitative study. Antimicrob Resist Infect Control. 2015; 21(4):30. doi: 10.1186/s13756-015-0073-4.

43. Van der Velden, Piipers EJ, Kuyvenhoven MM 2012, Effectiveness of physician-targeted interventions to improve antibiotic use for respiratory tract infections., Br J Gen Pract, 62(605): e810-e807, doi: 3399/bjgp12X659268

44. Smith D 2013. Health care consumer's use and trust of health information sources. https://doi.org/10.1179/1753807611Y.0000000010

45. Trifiletti DM 2015. Patient Trust- keeping it in the family. JAMA Oncol, 1(3): 279-80. doi: 10.1001/jamaoncol.2015.0370

46. Jasanoff, S. 2004,'The idiom of co-production”, in S Jasanoff (ed.) States of knowledge: The coproduction of science and social order, 1-12, Routledge, New York

47. Lang, D, Wiek, A, Bergmann, M, Stauffacher, M, Martens, P, Moll, $P$, et al. Trans disciplinary research in sustainability science: Practice, principles, and challenges'. Sustainability Science. 2012; 7: 25-43. https://doi.org/10.1007/s11625-011-0149-x

Page $19 / 20$ 
48. Moser, S 2016, 'Can science on transformation transform science? Lessons from co-design', Current Opinion in Environmental Sustainability, vol. 20 pp.106-115.

https://doi.org/10.1016/j.cosust.2016.10.007

49. Fatemeh Soleymani F, Rashidian, A, Dinarvand, R, Kebriaeezade1, A, Hosseini, A \& Mohammad Abdollahi, M 2012, 'Assessing the effectiveness and cost-effectiveness of audit and feedback on physician's prescribing indicators: study protocol of a randomized controlled trial with economic evaluation', DARU Journal of Pharmaceutical Sciences, 20, No.1,88. doi: 10.1186/2008-2231-20-88

50. Mohagheghi M, Mosavi-Jarrahi ,A, Khatemi-Moghaddam ,M, Afhami, S, Khodai, S \& Azemoodeh, O, 2005, 'Community-based outpatient practice of antibiotics use in Tehran'. Pharmacoepidemiol Drug Saf, 14, no.2, pp. 135-138.

51. Esmaily, H, Silver, I, Shiva, S, Gargani, A, Maleki-Dizaji, N, Al-Maniri ,A, Wahlstrom, R 2010, 'Can rational prescribing be improved by an outcome-based educational approach? A randomized trial completed in Iran', J Contin Educ Health Prof, vol.7, no. 944. doi: 1186/1756-0500-7-944

52. Henry, K \& McMillan, A 2014,'Metronidazole intravenous formulation use in in-patients in Kapkatet District Hospital, Kenya: a best practice implementation project', JBI Database of Systematic Reviews \& Implementation Reports, 12, no.3, pp. 419-432.

53. Saeed, T, Hafez, S, Kandeel, A, El-kholy, A, Ismail, G, Aboushady, M, Attia, E, Hassaan, A, Abdel-Atty, O, Elfekky, E, Girgis, S, Ismail, A. Abdou, E, Okasha, O \& Talaat ,M 2015, 'Antimicrobial stewardship to optimize the use of antimicrobials for surgical prophylaxis in Egypt: A multicenter pilot intervention study, American Journal of Infection Control',vol 43, no. 11,pp. 367-371. doi:

10.1016/j.ajic.2015.07.004.

54. Goossens, H, Ferech, M, Vander Stichele, R, Elseviers, M; ESAC Project Group. Outpatient antibiotic use in Europe and association with resistance: a cross-national database study. Lancet. 2005; 365(9459):579-587.

55. Dar OA, Hasan, R, Schlundt, J, Harbarth, S, Caleo, G. Dar FK, et al. Exploring the evidence base for national and regional policy interventions to combat resistance. Lancet. 2016; 387(10015): 285-289. doi: 10.1016/S0140-6736(15)00520-6.

56. Spence Laschinger HK, Leiter, MP, Day, A, Gilin-Oore, D Mackinnon, SP, Building Empowering Work Environments That Foster Civility And Organizational Trust Testing an Intervention Nursing Research September/October 2012 Vol 61, No 5, 316-325.

57. Morgenroth, T., Ryan, M. K., \& Peters, K. (2015, November 23). The Motivational Theory of Role Modeling: How Role Models Influence Role Aspirants' Goals. Review of General Psychology. Advance online publication. http://dx.doi.org/10.1037/gpr0000059

\section{Supplementary Files}

This is a list of supplementary files associated with this preprint. Click to download.

- Checklistforqualitativeresearch.docx 